\title{
The Brain and Heart Muscle Tissue Hydration Sensitivity to Painless and Painful Hot Plate Heating of Rats
}

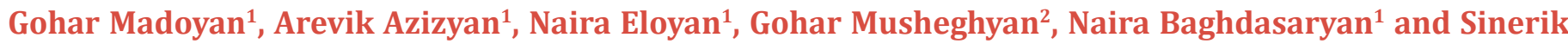 \\ Ayrapetyan $^{1 *}$
}

${ }^{1}$ Department of Biophysics, Armenia

${ }^{2}$ Department of Biology, Chemistry and Geography, Armenia

*Corresponding author: Sinerik Ayrapetyan, Department of Biophysics, UNESCO Chair - Life Sciences International Postgraduate Educational Center Yerevan, Armenia.

\begin{abstract}
Previously, it was hypothesized that the over-hydration of excitable cells leading to the abnormal excitation of the membrane, which transmits the nerve signal to the central neuronal system, can generate pain sensation. To check this hypothesis by means of painless and painful heating of experimental animals with "hot plate" method the hydration sensitivity of several body areas to pain was studied. For this purpose, the effect of painless $\left(38^{\circ} \mathrm{C}\right)$ and painful $\left(52.2^{\circ} \mathrm{C}\right)$ heating on rats' heart muscle, brain cortex and cerebellum tissue hydration was investigated in different experimental media (10-4M and 10-9M ouabain containing physiological solution) by means of "hot plate" method. The obtained data allow us to conclude the following: the hydrations of heart muscle, brain cortex and cerebellum tissues have different sensitivities to painful and painless heating, the hydration sensitivity of heart muscle tissue could serve as a primary marker for heating and the hydration of cerebellum tissue could serve as a marker for heating-induced pain threshold. Both painful and painless heating lead to the elevation of tissue hydration and their difference is suggested as a marker for pain sensation. Thus, the hydration is an extra-sensitive marker for pain sensation.
\end{abstract}

Keywords: Cell hydration; Hot plate; Lactate $\mathrm{Na}+/ \mathrm{K}+-\mathrm{ATPasa}$; Camp; $\mathrm{Na}+/ \mathrm{Ca}^{2+}$ exchange; Painless and painful heating

\section{Introduction}

From the biophysical point of view the pain is considered to be an abnormal excitation of nerve ending, which transmits the nerve impulse to pain centers in central neuronal system (CNS) [1]. Since the pain can be provoked by different phenomena, starting from mechanical damage to the breakdown of different metabolic pathways, there must be a common cellular mechanism through which the various physical, chemical and metabolic factors could generate the abnormal excitation of the nerve ending membrane. As the pain sensation could be modulated by different chemical and physical signals, having even less intensity than the thermal threshold, it indicates that such a target should have a quantummechanical nature [2,3]. However, the cellular and molecular mechanisms underlying the pain sensation to under-threshold chemical and physical signals are not revealed yet.
Previously, the cell hydration was suggested as a quantummechanical sensor through which the close-talk between intracellular metabolism and extracellular medium were realized [4]. It was shown that there have been a close correlation between cell hydration and membrane excitation because of the surfacedependent changes of the number of ionic channels and receptors in the membrane $[5,6]$. It was also shown that "net water uptake" by cell had activation effect on the inward ionic ( $\mathrm{Na}+$ and $\mathrm{Ca} 2+)$ currents. Therefore, it is hypothesized that the cell hydration can be considered a primary quantum-sensitive target through which the membrane excitability (nociception) could be modulated.

It is known that cell hydration can be realized by net water uptake or by generation of the intracellular water during oxidative 
processes. Therefore, to check the hypothesis the hydration sensitivity of heart and brain (cortex and cerebellum) tissues to pain threshold has been studied by means of painless and painful heating of animals with "hot plate" method. The choice of these tissues is dictated by the statement that a) the heart muscle exhibits high sensitivity to any small changes in blood composition, b) stress centers are localized in cortex and c) the cerebellum contributes to coordination, precision, and accurate timing, i.e. plays an important role in motor control particularly in our experimental case, e.g. while jumping or leg rising. As "hot plate" method is used as a paininducing factor to distinguish the differences between painless and painful heating, the temperature of "hot plate" has been chosen equal to $38{ }^{\circ} \mathrm{C}$ - rat body (painless) and $52.2^{\circ} \mathrm{C}$-heating, (the painful temperature for pain threshold assessment).

\section{Materials and Methods}

All procedures performed on animals were carried out following the protocols approved by Animal Care and Use Committee of Life Sciences International Postgraduate Educational Centre (LSIPEC, Yerevan, Armenia).

\section{Animals}

The experiments were performed on adult male albino rats (8 weeks old) weighing 100-120g. The animals were regularly examined, kept in the control of the veterinary in LSIPEC and reserved in a specific pathogen-free animal room under optimum conditions of 12-h light/dark cycle, at temperature of $21^{\circ} \mathrm{C}$, a relative humidity of $50 \%$, and were fed ad libitum on a standard laboratory chow and tap water.

\section{Chemicals}

Tyrode's physiological solution (PS) containing (in $\mathrm{mM}$ ): $\mathrm{NaCl}-$ 137, KCl-5.4, CaCl2 - 1.8, MgCl2-1.05, C6H12O6-5, NaHCO3- 11.9 and $\mathrm{NaH} 2 \mathrm{PO} 4-0.42$ and adjusted to $\mathrm{pH} 7.4$ with $\mathrm{NaOH}$. All chemicals were obtained from "Medisar" Industrial Chemical Importation Company (Yerevan, Armenia).

The PS containing 10-9M and 10-4M concentrations of ouabain (Sigma-Aldrich, USA) as well as the ouabain-free PS were used for tissue incubation.

\section{Temperature treatment of rat on "hot plate"}

The "hot plate" test was conducted by a specific setup constructed in LSIPEC and approved by the Ethic Committee of UNESCO Chair in Life Sciences. The setup consisted of the plexi cage, with a brass bottom and a thermometer inside. The brass was adjusted to three different temperature conditions a) sham - $210 \mathrm{C}$ (room temperature), b) painless $-38{ }^{\circ} \mathrm{C}$ (body temperature) and c) painful $-52.2^{\circ} \mathrm{C}$ (usually used for estimation of the pain threshold). According to the "hot plate" method the pain threshold could be assessed visually by estimation of the latency period (in sec.), which is the time elapsed until one of the following responses: licking the feet, jumping or rapidly stamping the feet. In our experiments the latency periods were measured only in $52.2{ }^{\circ} \mathrm{C}$ groups, while in case of $21^{\circ} \mathrm{C}$ and $38^{\circ} \mathrm{C}$ groups the rats were placed in this chamber (Figure 1) for $1 \mathrm{~min}$. (an usual duration in estimation of pain threshold) (Figure 1).

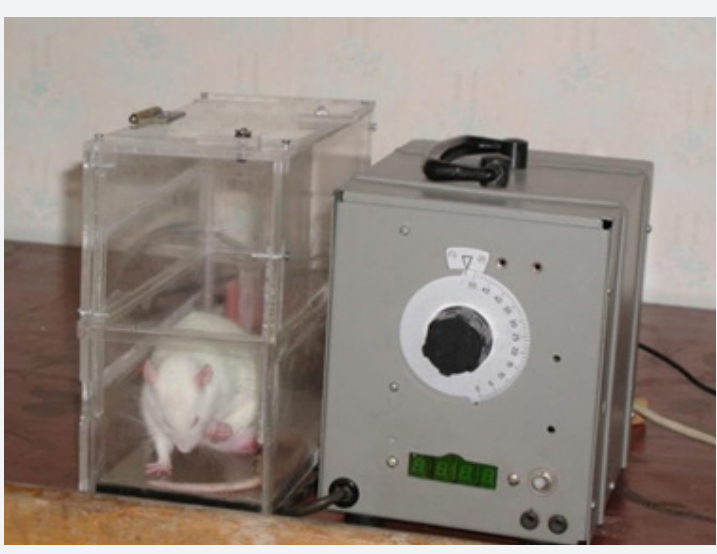

Figure 1: The "hot plate" setup for determination of pain threshold of rats.

\section{Tissue preparation}

To avoid the anesthetic effect on the initial functional state of the animal $[7,8]$ in the present experiments we preferred to use "sharp freezing" method for killing [9].Then the rats were decapitated and the sampled heart muscle, brain cortex and cerebellum tissues of animals were preliminarily placed in three temperature conditions (room, painless and painful) for $1 \mathrm{~min}$ and, were incubated in the PS containing 10-9M, 10-4M ouabain, as well as in ouabain-free PS for $30 \mathrm{~min}$. In order to remove surface-adherent and extra-cellular tracers (ouabain), after incubation the samples were washed three times with PS for $15 \mathrm{~min}, 5 \mathrm{~min}, 5 \mathrm{~min}$ in all experiments, respectively. After that the wet weight (w.w.) of samples was determined (time duration for these processes was less than $1 \mathrm{~min}$. for 30 samples). Similar procedures were performed with the samples of control and experimental groups.

\section{Determination of lactate concentration in rat blood}

The estimation of lactate concentration in blood was performed by a well-known "colorimetric assay" method using the Roche Cobas c311 automated biochemical analyzer system. The blood was collected immediately after decapitation.

\section{Definition of water content of tissues}

The water content was calculated by "tissue drying" method [10]. After measuring the tissue w.w., it was dried in thermostat (Factory of Medical Equipment, Odessa, Ukraine) during 24h at $1050 \mathrm{C}$ for determination of dry weight (d.w.). The quantity of water in $1 \mathrm{~g}$ of d.w. of tissue was counted by the following equation: (w.w. - d.w.)/d.w.

\section{Statistical analysis}

The Sigma-Plot (version 8.02A) was used for data analysis. The statistical significance between sham and experimental groups was calculated via student's t-test and expressed in graphs supported by the following symbols $-{ }^{*} \mathrm{p}<0.05,{ }^{* *} \mathrm{p}<0.01,{ }^{* * *} \mathrm{p}<0.001$.

\section{Result}

The comparative analyses of lactate content changes in the blood of exposed rats on "hot plate" setup for $1 \mathrm{~min}$, where the temperature of the plate was adjusted to three preliminary chosen 
values $\left(210 \mathrm{C}\right.$ (sham), $38{ }^{\circ} \mathrm{C}$ (painless) and $52.2{ }^{\circ} \mathrm{C}$ (painful)) are presented in (Figure 2). According to the obtained data the animal placement on the "hot plate" with $38{ }^{\circ} \mathrm{C}$ for $1 \mathrm{~min}$. has led to the decrease of the lactate concentration in rat blood by $27.82 \%$ as compared to sham, while in case of $52.2^{\circ} \mathrm{C}$-adjusted "hot plate" the increase of the lactate concentration by $31.9 \%$ has been recorded. In the next series of experiments the water contents of the sampled heart muscle, brain cortex and cerebellum tissues of animals preliminarily placed on $21{ }^{\circ} \mathrm{C}-, 38{ }^{\circ} \mathrm{C}$ - and $52.2^{\circ} \mathrm{C}$-adjusted "hot plate" (for $1 \mathrm{~min}$ ) has been studied (Figure 2).

As it can be seen in (Figure 3a), in case of $21{ }^{\circ} \mathrm{C}$ no changes are recorded, while in $38{ }^{\circ} \mathrm{C}$ and $52.2{ }^{\circ} \mathrm{C}$ groups' contradictory effects are manifested, i.e. $38{ }^{\circ} \mathrm{C}$ treatment causes the elevation of hydration by $3.6 \%$, and $52.2{ }^{\circ} \mathrm{C}$ decreases the elevation of heart muscle hydration by $2.1 \%$. All sample groups are compared to the intact group. In this group the hydration of heart muscle is assessed without "hot plate" application.

In brain cortex tissue samples have pronounced hydration in all temperatures compared with intact group by $4.9 \%, 7.3 \%$ and $3.7 \%$, correspondingly (Figure 3b).

The cerebellum exhibits no statistically significant changes in $21{ }^{\circ} \mathrm{C}$ and $38{ }^{\circ} \mathrm{C}$ groups, and only $52.2{ }^{\circ} \mathrm{C}$ heating elevates the hydration level by $10.4 \%$ (Figure 3c), which can be explained by the fact that the cerebellum, being the center of the animal body equilibrium, is excited as a result of animal leg raising in response to the high temperature (painful) impact. Further experiments performed with the incubation of samples in PS for $30 \mathrm{~min}$. have shown that as a result of all temperature treatments of rats, the heart muscles express dehydration in all cases, which can be conditioned by depression of metabolism and calcium accumulation as a consequence of incubation in the room condition (Figure $3 \& 4$ ).

In brain tissues (cortex and cerebellum) another picture is observed. Both represent hydration after $380 \mathrm{C}$ and $52.2{ }^{\circ} \mathrm{C}$ treatment and after incubation in PS (Figure $4 \mathrm{~b} \& 4 \mathrm{c}$ ), however in $21{ }^{\circ} \mathrm{C}$ cortex and cerebellum are dehydrated. The following experiments were performed with the use of high (10-4M) and low (10-9M) doses of ouabain containing PS. In both cases heart muscle, brain cortex and cerebellum tissue samples of the three investigated groups $\left(21{ }^{\circ} \mathrm{C}-, 38{ }^{\circ} \mathrm{C}-\right.$ and $52.2{ }^{\circ} \mathrm{C}$-heated $)$ were incubated in above mentioned solutions during $30 \mathrm{~min}$., after that they were washed in PS. As Figure 5 indicates 10-4M ouabain leads to statistically significant hydration in heart muscle, brain cortex and cerebellum tissues. The horizontal line represents the data on the animals preliminarily placed on $21{ }^{\circ} \mathrm{C}$ "hot plate" and after decapitation, sampled heart muscle, brain cortex and cerebellum tissues were incubated in $10 \mathrm{ml}$ PS for $30 \mathrm{~min}$. In case of incubation of samples in 10-9M ouabain containing PS the hydration of all tissues was manifested in $38{ }^{\circ} \mathrm{C}$ and $52.2{ }^{\circ} \mathrm{C}$ groups only, while in $21^{\circ} \mathrm{C}$ group heart and cerebellum tissues were dehydrated and the brain cortex was non-statistically hydrated (Figure $5 \& 6$ ).

\section{Discussion}

It is known that the increase of lactate concentration in blood is one of the markers for pain nociception and stress of the organism.
Based on this, in the first step of our experiments the lactate concentration is estimated in rat blood preliminary subjected to free temperature conditions in order to reveal the existence of stress in organism. The decreased lactate concentration upon the effect of 38 ${ }^{\circ} \mathrm{C}$ compared with $21^{\circ} \mathrm{C}$ can be explained by temperature -induce increase mitochondrial function leading to depression of the lactate activity. The fact that $52.2^{\circ} \mathrm{C}$ (painful) treatment of animal leads to the sharp elevation of the lactate concentration (Figure 2) allows us to suggest that pain stress leads to active lactate dehydrogenase activity probably by the effect released stress hormone in blood.

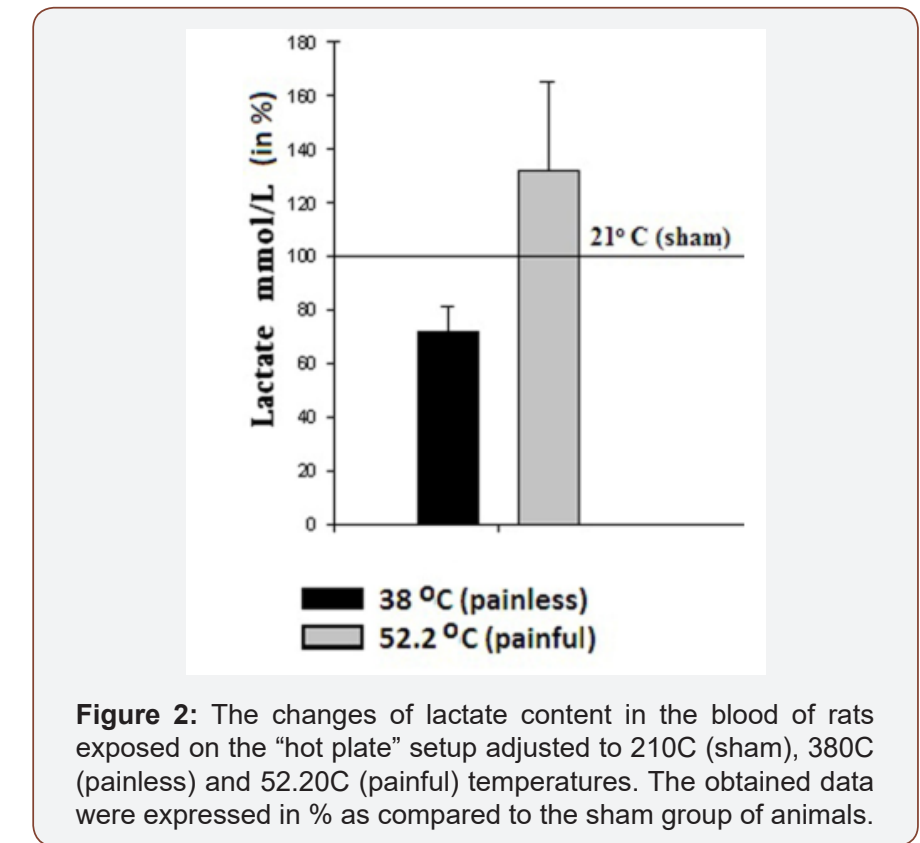

Previously, it has been suggested that cell overhydration has a key role in neuronal cell excitation generation and, consequently, in pain sensation processes [11]. Meanwhile, it has been deduced that the water contents in cell serves as a quantum-mechanical sensor and displays sensitivity to various chemical and physical factors. Based on this, in our experiments the changes of tissue hydration in painful and painless heating conditions have been investigated in order to clarify whether the cell hydration could serve as a marker for pain sensation. At the same time, based on the principle of "hot plate" method, which assesses the latency period of standing the animal on the $52.2^{\circ} \mathrm{C}$ painful-adjusted plate till it licks the leg or jumps, it becomes clear that at least two parts of the brain (the cortex - where the stress centers are localized and the cerebellum- which is responsible for the animal body equilibrium) are involved in the estimation of the animal pain threshold via "hot plate" method. From the other side the heart muscle exhibits high sensitivity to any small changes in blood composition including lactate concentration. Therefore, in further experiments dedicated to identify the pain-induced changes of water contents in tissues, these 3 types of samples have been chosen.

The comparative study of the sampled heart muscles of animals preliminarily placed on $21{ }^{\circ} \mathrm{C}-, 38{ }^{\circ} \mathrm{C}$ - and $52.2^{\circ} \mathrm{C}$-adjusted "hot plate" (for $1 \mathrm{~min}$.) has shown contradictory effects in 380C and $52.2{ }^{\circ} \mathrm{C}$ groups (Figure 3a) i.e. $38{ }^{\circ} \mathrm{C}$ treatment causes elevation of heart muscle tissue hydration and $52.2^{\circ} \mathrm{C}$ decreases it. In norm, 
the activation of cell metabolism accompanied with the decrease of the lactate concentration in blood brings to endogenous water production and elevation of cell hydration (which was mentioned in 380C groups), while the applied stress, which elevates the lactate concentration, causes shrinkage of heart muscle tissue though accumulation of Ca ions in cell (Figure 3).

The brain cortex displays hypersensitivity and the hydration of samples is recorded in all temperature-treated cases (Figure 3b), while the cerebellum exhibits statistically insignificant changes in $21{ }^{\circ} \mathrm{C}$ and $38{ }^{\circ} \mathrm{C}$ groups, and only $52.2{ }^{\circ} \mathrm{C}$ heating elevates the hydration (Figure 3c), which can be explained by the fact that the cerebellum, being the center of the animal body equilibrium, is excited as a result of animal leg raising in response to high temperature (painful) impact. Thus, based on the obtained results regarding the lactate concentration and tissue hydration could be concluded that cell hydration is sensitive to painless as well as painful heating. The fact that both heating-induced effects on the lactate concentration are in more correspondence to the data on the heart muscle then brain tissues allow us to assume that the signal transmission is probably realized by neuro-hormonal pathway.

As it has been described in "Introduction" section, the intracellular water content could be elevated by two pathways, having opposite directions: extracellular water uptake by cell as a result of osmotic gradient, and endogenous water release as a result of cell metabolism. In regulation of cell hydration, the $\mathrm{Na}+$ / $\mathrm{K}+$-ATPase has a key role, which is realized by the ionic transporting mechanism as well as through the intracellular signaling system controlling the cell metabolic activity. It has been shown that signaling function of $\mathrm{Na}+\mathrm{K}+-\mathrm{ATPa} e$ [12] is realized through cyclic nucleotides-dependent $\mathrm{Na}+/ \mathrm{Ca}^{2+}$ exchange having a crucial role in intracellular Ca homeostasis. Previously, it has been indicated that $\mathrm{nM}$ concentration of ouabain stimulates the reverse mode of $\mathrm{Na}+/ \mathrm{Ca}^{2+}$ exchanger $\left(\mathrm{R} \mathrm{Na}+/ \mathrm{Ca}^{2+}\right)$. Despite the fact that $\mathrm{Na}+/ \mathrm{Ca}^{2+}$ exchange works in stoichiometry of $3 \mathrm{Na}+$ and $1 \mathrm{Ca}^{2+}[13]$ it could have hydration or dehydration effects depending on the initial functional state of the cells [14] i.e. intracellular $\mathrm{Ca}^{2+}$ concentration, as the latter has multi-poisoning effect on cell [15].
In order to find out whether the changes of water contents in tissue presented in Figure 3 are consequences of net water uptake or endogenous water release, in the further experiments it has been decided to incubate the samples of heart muscle, brain cortex and cerebellum tissues in two different conditions for pump functioning state (active and inactive). For this purpose, the 10-4M and 10-9M ouabain containing PS have been chosen. The first one inhibits the pump activity and stimulates exogenous water uptake by cell and the second one promotes the mitochondrial function without directly affecting the functional state of the pump. It is logical that the incubation process of samples during $30 \mathrm{~min}$. in certain solution should lead to side effects, which are conditioned by the depression of metabolism as a result of removing of tissue samples from the organism. However, the incubation of samples during $30 \mathrm{~min}$. was preferred to intraperitoneal injection because the presented article is dedicated to the investigation of pain, which can be also provoked by the injection that is not desirable for our case. In order to assess the incubation-induced changes of cell hydration, firstly the samples have been incubated in ouabainfree PS for $30 \mathrm{~min}$. as a control. The results have approved our assumptions mainly in case of heart samples: if in experiments without $30 \mathrm{~min}$. incubation (Figure 3a) the heart muscle hydration has opposite correlation to the lactate concentration, than after 30 min. incubation this effect has disappeared and dehydration of heart tissue samples in all temperature-treated cases has been observed. This phenomenon can be explained by the depression of metabolism and calcium accumulation as a consequence of sample incubation in room condition (Figure 4a). The changes on hydration level in brain tissues (cortex and cerebellum) after 30 min. incubation mostly mimic the tendency of hydration changes without PS incubation, and the only exception is recorded in cortex $21^{\circ} \mathrm{C}$ group (Figure 4 ). After the incubation in control PS, in further experiments the high (10-4M) doses of ouabain containing PS have been used as incubation solution. The results have shown that 10-4M ouabain elevates the water content of heart muscle, brain cortex and cerebellum tissues in all temperature-treated groups as compared to the PS-incubated samples (Figure 5).
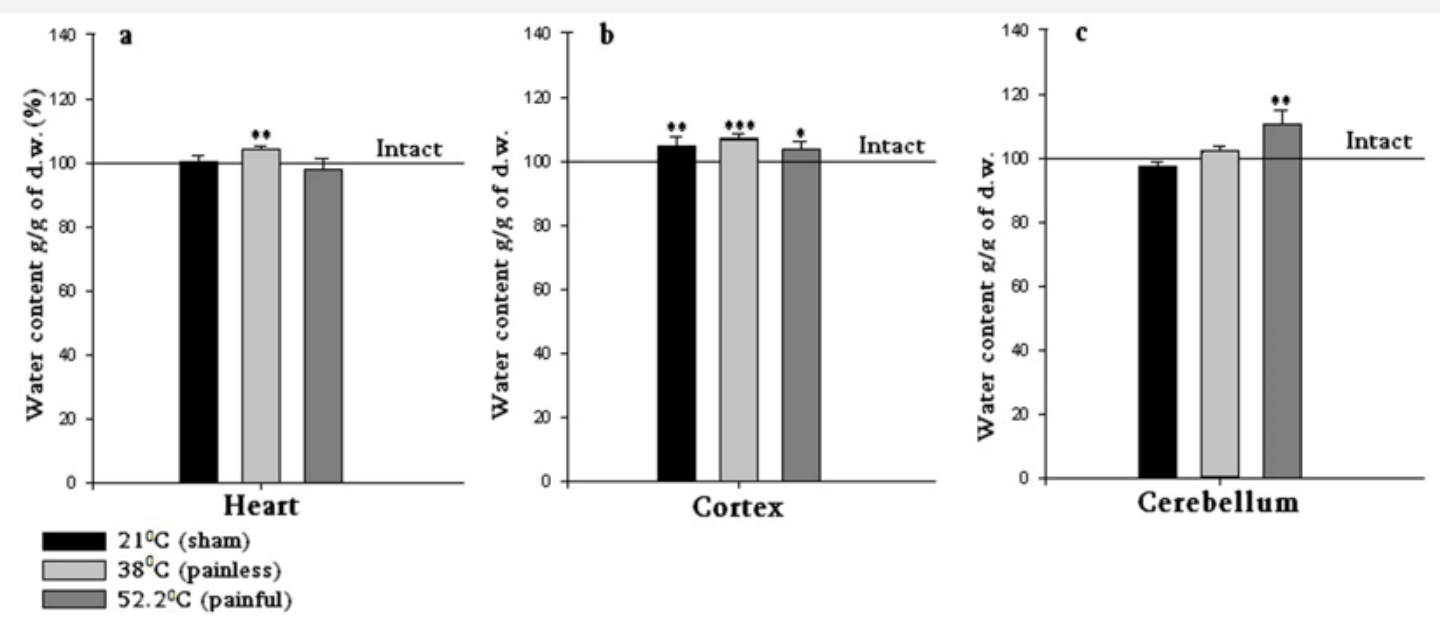

Figure 3: The water contents of heart muscle (a), brain cortex (b) and cerebellum (c) tissues of animals exposed on the "hot plate" adjusted to $210 \mathrm{C}$ (sham), $380 \mathrm{C}$ (painless) and $52.20 \mathrm{C}$ (painful) temperatures for $1 \mathrm{~min}$. The data were expressed in $\%$ and were compared to the intact group of animals without placement on the "hot plate" setup (the horizontal line marked as intact). 

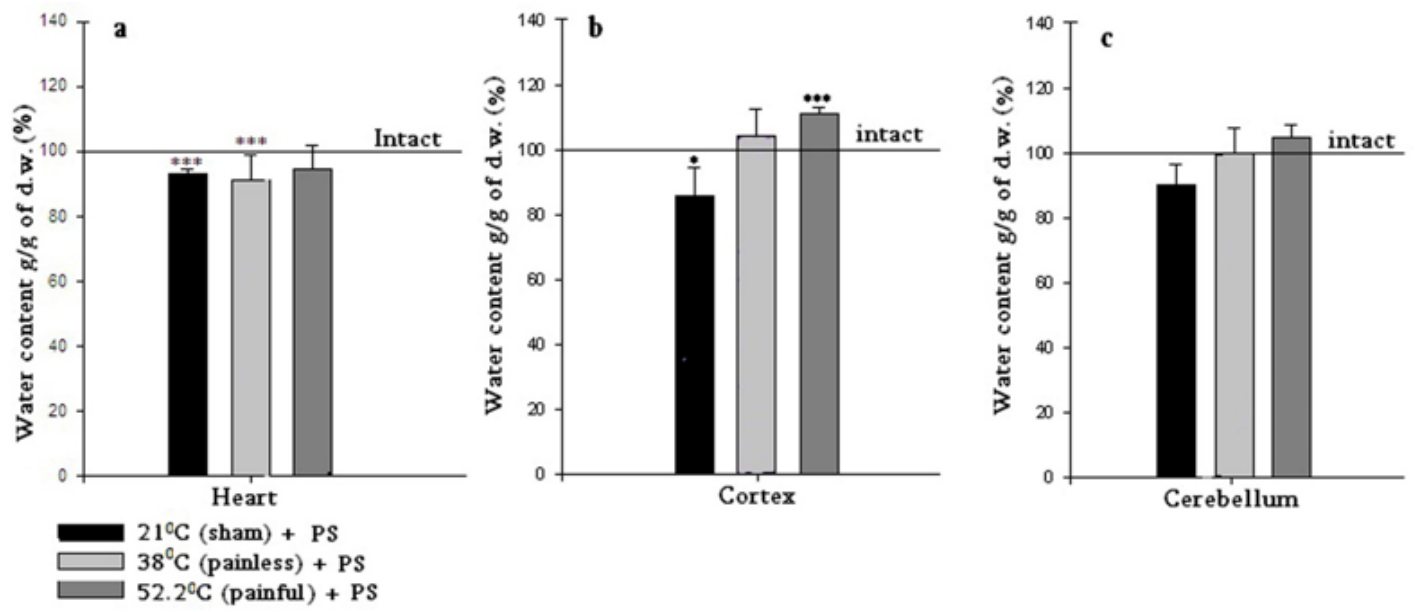

Figure 4: The water contents of heart muscle (a), brain cortex (b) and cerebellum (c) tissues incubated in PS for 30 min. after decapitation of the animals, which were preliminarily exposed by $210 \mathrm{C}(\mathrm{sham}), 380 \mathrm{C}$ (painless) and $52.20 \mathrm{C}$ (painful) temperatures for 1 min on the "hot plate". The data were expressed in $\%$ and were compared to intact group (horizontal line).
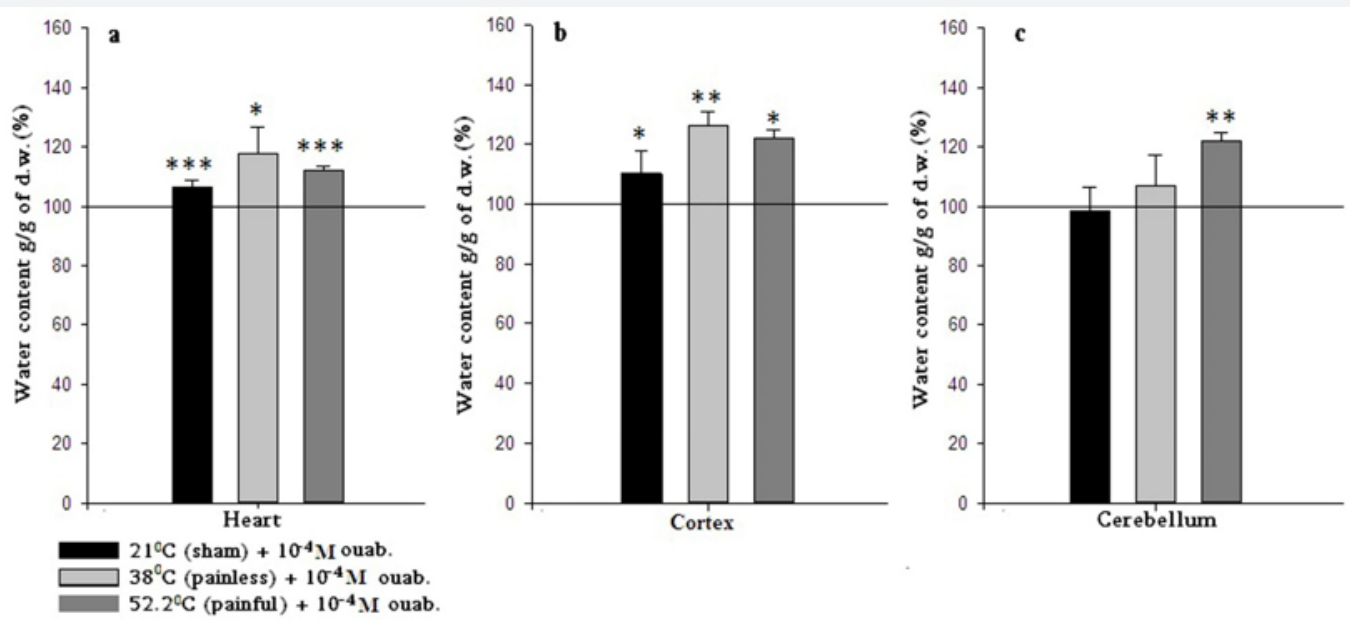

Figure 5: The water contents of heart muscle (a), brain cortex (b) and cerebellum (c) tissues incubated in PS containing 10-4M ouabain for 30 min. after decapitation of animals, which were preliminarily exposed on the "hot plate" adjusted to $210 \mathrm{C}$ (sham), 380C (painless) and $52.20 \mathrm{C}$ (painful) temperatures for $1 \mathrm{~min}$. The data were expressed in \% and were compared to PS-incubated sham group of animals (horizontal line).

Since 1979 Ayrapetyan and Suleymanyan on isolated neuron of Helix pomatia and Carpenter in 1992 on neurons from isolated ganglia of Aplysiacalifornica have shown that $10-4 \mathrm{M}$ ouabaininduced inhibition of $\mathrm{Na}+\mathrm{K}+$ pump activity leads to elevation of cell hydration $[16,17]$. Our results on the rat brain cortex and cerebellum tissues (Figure $5 b$ \& $5 c$ ) coincide with the literature data on $10-4 \mathrm{M}$ ouabain-induced inhibition of $\mathrm{Na}+\mathrm{K}+$ pump activity leading to elevation of neuronal cell hydration of mollusks. At the same time, it has been shown that $10-4 \mathrm{M}$ ouabain-induced $\mathrm{Na}+\mathrm{K}+$ pump inhibition brings to the elevation of intracellular Ca concentration in rat cardiac myocytes [18]. As it has been described above, the decrease of heart muscle hydration presented in (Figure 4a) could be explained by the elevation of $\left[\mathrm{Ca}^{2+}\right]$ i induced contraction of muscle myocyte and cell dehydration. However, our obtained results on the effect of 10-4M ouabain on rat heart muscle tissue have shown statistically significant hydration (Figure 5a). At the first sight it seems that there is a contradiction between explanations of PS incubation-induced heart muscle dehydration (which was commented as consequence of the Ca accumulation in cell) and $10-4 \mathrm{M}$ ouabain-induced heart hydration (which was accompanied by the Ca influx). However, it should be taken into consideration that in $10-4 \mathrm{M}$ ouabain group the incubationinduced inhibition (during $30 \mathrm{~min}$.) of cell metabolism and $\mathrm{Ca}$ accumulation process are deepening in case of pump inactivation as a result of $10-4 \mathrm{M}$ ouabain presence in the solution. According to the literature data in case of high level of $\left[\mathrm{Ca}^{2+}\right] \mathrm{I}$, these ions bind with calmodulin [19-21] and through the calmodulin-NO-cGMP cascade, tilt the $\mathrm{Na}+/ \mathrm{Ca}^{2+}$ exchanger from reverse to forward mode and, as a consequence, stimulate $\mathrm{Ca}^{2+}$ efflux from the cell. Due to $\mathrm{F} \mathrm{Na}+/ \mathrm{Ca}^{2+}$ exchanger stoichiometry (i.e. $3 \mathrm{Na}+-$ inward and $1 \mathrm{Ca}^{2+}$ - outward) it leads to the exogenous water influx into the cell. Via this cell metabolic chain scheme, the heart muscle tissue hydration after incubation in 10-4M ouabain containing PS of all investigated groups could be explained.

In the last series of experiments $10-9 \mathrm{M}$ ouabain containing PS has been used as the main solution for sample incubation. According to the obtained result, 10-9M ouabain-induced changes in tissue hydration are similar to $10-4 \mathrm{M}$-induced effects in $38^{\circ} \mathrm{C}$ and $52.2{ }^{\circ} \mathrm{C}$ groups. Recent studies dedicated to the investigations 
of different doses of ouabain-induced effect on cells and organism have shown that on the contrary to high doses of ouabain the nanomolar concentration of these substances does not inhibit but either non-directly increases the $\mathrm{Na}+\mathrm{K}+$-ATPase activity [22] or has no effect on the functional state of the Na+/K+-pump [23]. The studies of Saghian and the colleagues on snail neurons have shown that $<10-9 \mathrm{M}$ ouabain has activation effect on $22 \mathrm{Na}+$ efflux in exchange to $\mathrm{Ca}^{2+}$ uptake ( $\mathrm{R} \mathrm{Na}+/ \mathrm{Ca}^{2+}$ exchange), without changing $\mathrm{Na}+/ \mathrm{K}+$-pump activity. According to the last experimental studies low and high doses of ouabain lead to cell hydration, furthermore, 10-9M-induced elevation of intracellular water contents exceeds 10-4M-induced effect [24]. Based on these data Heqimyan's group has concluded that the abovementioned doses of ouabain-induced influence on cell metabolism are realized by different pathways. Apart from this, nM ouabain-induced activation of $\mathrm{RNa}+/ \mathrm{Ca}^{2+}$ exchange is accompanied by the increase of intracellular contents of cAMP, which stimulates $\mathrm{Ca}^{2+}$ - ATPase located in the membrane of endoplasmic reticulum (ER), which in its turn accumulates $\mathrm{Ca}^{2+}$ from cytoplasm into ER. It is demonstrated that the close contact between ER and mitochondria plays a key role in decoding $\mathrm{Ca}^{2+}$ mediated apoptotic signals $[25,26]$. The mitochondrial function is stimulated through the junction between ER and mitochondria [27] bringing to the endogenous water production and elevation of hydration level of the cell.

Thus, based on the data in Figure $5(\mathrm{Na}+\mathrm{K}+$ in inhibited state) and Figure $6(\mathrm{Na}+/ \mathrm{K}+$ in normal state), it can be issued that the pronounced hydration has a $\mathrm{Na}+\mathrm{K}+$ pump-independent character and is conditioned by the $\mathrm{F} / \mathrm{R}$ functional modes of $\mathrm{Na}+\mathrm{Ca}^{2+}$ exchanger. Regarding to the pain-induced effect at the presence of high and low doses of ouabain it is worth to note that though according to the Van't Hoff rule it was predicted that the $52.2{ }^{\circ} \mathrm{C}$ -induced hydration should exceed the 380C-induced one, the obtained results have shown the deficiency of the 52.2C-induced effect in both incubation groups (10-4M and 10-9M), which is referred to pain in case of $52.2{ }^{\circ} \mathrm{C}$ treatment. The pain-induced excitation leading to dehydration compared to $38{ }^{\circ} \mathrm{C}$ probably can be explained by the depressed metabolic activity dramatically changing ionic homeostasis.
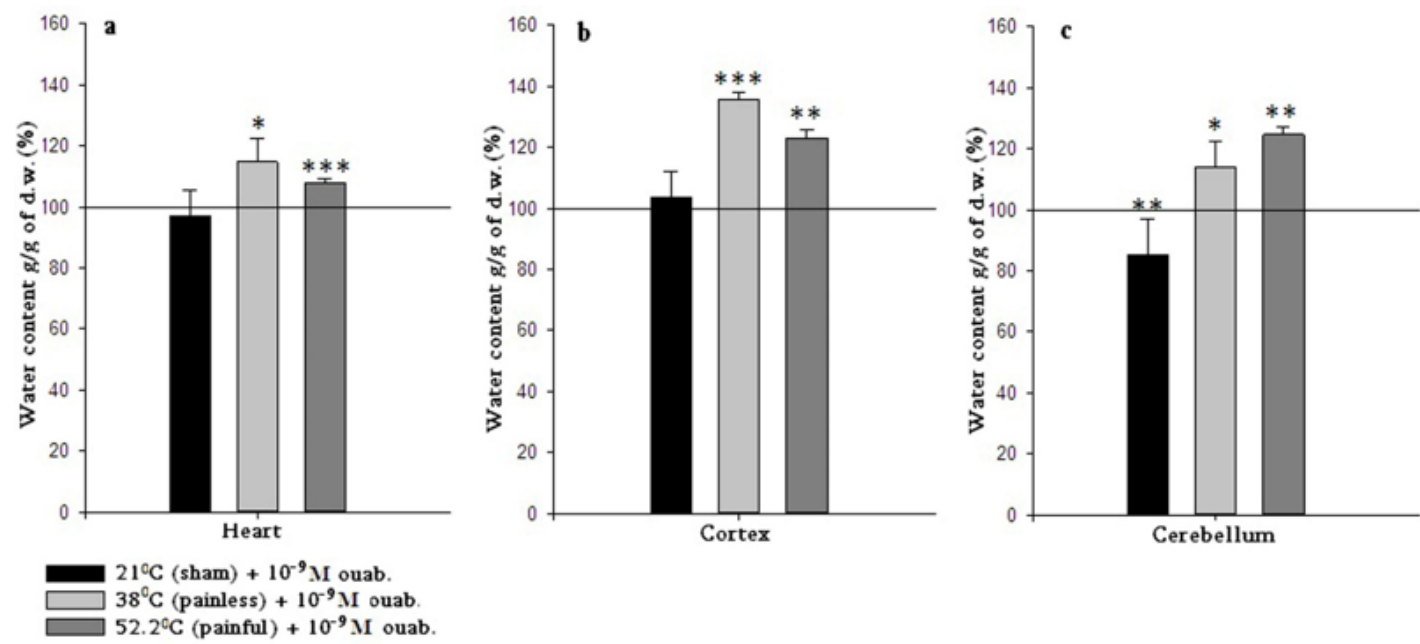

Figure 6: The water contents of heart muscle (a), brain cortex (b) and cerebellum (c) tissues incubated in PS containing 10-9M ouabain for 30 min., after decapitation of animals, which were preliminarily exposed on the "hot plate" adjusted to $210 \mathrm{C}$ (sham), $380 \mathrm{C}$ (painless) and $52.20 \mathrm{C}$ (painful) temperatures for $1 \mathrm{~min}$. The data were expressed in \% and were compared to PS-incubated sham group of animals (horizontal line).

The fact that painful heating in 10-4M and 10-9M incubation groups has similar effects, allows us to conclude that the pain sensation does not depend on the functional state of $\mathrm{Na}+\mathrm{K}+$ pump and is targeted to inhibit the metabolic processes in cell. The more detailed investigations of presented phenomena will be the subject of our further studies.

\section{Conclusion}

The hydration of heart muscle, brain cortex and cerebellum tissue is sensitive to painless and painful heating. As the hydration of heart muscle is changed as a result of painless heating it could be assumed that signal transmission is probably realized by nonneuronal pathway. The hydration of cerebellum could be the marker for pain threshold assessment by "hot plate" method. Both painful and painless heating lead to the elevation of tissue hydration and their difference is suggested as a marker for pain sensation. Thus, the hydration is suggested as an extra-sensitive marker for pain sensation.

\section{Acknowledgement}

None.

\section{Conflict of Interest}

No conflict of interest.

\section{References}

1. Ayrapetyan SN, Arvanov VL, Maginyan SB, Azatyan KV (1985) Further study of the correlation between Na-pump activity and membrane chemosensitivity. Cell Mol Neurobiol 5(3): 231-243.

2. Ayrapetyan S (2015) The Dysfunction of Metabolic Controlling of Cell Hydration Precedes Warburg Phenomenon in Carcinogenesis. J Bioequiv Availab 7(1): 1-2

3. Ayrapetyan $\mathrm{S}$ (2018) The net water uptake by excitable cells is a primary mechanism for pain signal generation. J Bioequiv Availab 10(3). 
4. Nikoghosyan A, Narinyan L, Heqimyan A and Ayrapetyan S (2018) The Quantum-Mechanical Sensitivity of Cell Hydration in Mammals. Open Journal of Biophysics 8: 104-116.

5. Ayrapetyan SN, Suleymanyan MA, Saghian AA, Dadalian SS (1984) Autoregulation of the Electrogenic Sodium Pump. Cell Mol Neurobiol 4(4): 367-383.

6. Ayrapetyan SN, Rychkov GY, Suleymanyan MA (1988) Effects of water flow on transmembrane ionic currents in neurons of Helix pomatia and in Squid giant axons. Comp Biochem Physiol 89(2): 179-186.

7. Adams HR, Parker JL, Mathew BP (1977) The influence of ketamine on inotropic and chronotropic responsiveness of heart muscle. J Pharmacol Exp Ther 201(1): 171-183.

8. Akbar L, Sarioğlu Y, Utkan T (1992) Effect of ketamine on contractile performance of isolated frog myocardium and comparison of ketamine thiopental and droperidol. Mater Med Pol 24(1): 32-34.

9. Takahashi R, Aprison M (1964) Acetylcholine content of discrete areas of the brain obtained by a near-freezing method. J Neurochem 11: 887898.

10. Adrian RH (1956) The effect of internal and external potassium concentration on the membrane potential of frog muscle. J Physiol 133(3): 631-658.

11. Ayrapetyan S (1998) The Application of the Theory of Metabolic Regulation to Pain. In: Ayrapetyan S and Apkarian (eds). Pain mechanism and management IOS press, USA, pp. 03-14.

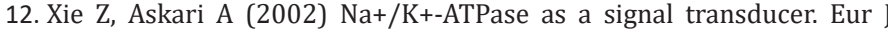
Biochem 269(10): 2434-2439.

13. Baker PF, Blaustein MP, Hodgkin AL, Steinhardt RA (1969) The influence of calcium on sodium efflux in squid axons. J Physiol 200(2): 431-458.

14. Ayrapetyan S, Heqimyan A, Nikoghosyan A (2012) Age-Dependent Brain Tissue Hydration, Ca Exchange and their Dose- Dependent Ouabain Sensitivity. J Bioequiv Availab 4(5): 60-68.

15. Skou JC (1957) The influence of some cations on an adenosine triphosphatase from peripheral nerves. Biochim Biophys Acta 23(2): 394-401.
16. Ayrapetyan S, Sulejmanyan M (1979) On the pump-induced cell volume changes. Comp Biochem Physiol 64(4): 571-575.

17. Carpenter D, Fejtl M, Ayrapetyan S, Szarowski D, Turner J (1992) Dynamic changes in neuronal volume resulting from osmotic and sodium transport manipulations. Acta Biol Hung 43(1-4): 39-48.

18. Tian J1, Gong X, Xie Z (2001) Signal-transducing function of Na-K-ATPase is essential for ouabain's effect on [Ca2+]i in rat cardiac myocytes. Am J Physiol Heart Circ Physiol 281(5): H1899-H1907.

19. Nikoghosyan A, Heqimyan A, Ayrapetyan S (2016) Primary mechanism responsible for age-dependent neuronal hydration. Intern J Basic Applied Sci 5(1): 5-14.

20. Azatian KV, White AR, Walker RJ, Ayrapetyan SN (1998) Cellular and molecular mechanisms of nitric oxide-induced heart muscle relaxation. Gen Pharmac 30(4): 543-553.

21. Brini M, Carafoli E (2009) Calcium pumps in health and disease. Physiol Rev 89(4): 1341-1378.

22. Antolović R (2006) Low nanomolar concentrations of ouabain may induce higher activity of the $\mathrm{Na}+/ \mathrm{K}+-$ ATPase in human erythrocytes. Veterinarski arhiv 76(6): 489-49.

23. Saghian AA, Ayrapetyan SN, Carpenter DO (1996) Low concentrations of ouabain stimulate $\mathrm{Na} / \mathrm{Ca}$ exchange in neurons. Cell Mol Neurobiol 16(4): 489-498.

24. Heqimyan A, Narinyan L, Nikoghosyan A, Ayrapetyan S (2015) Agedependent magnetic sensitivity of brain and heart muscles. In: Markov M (ed.) Electromagnetic Fields in Biology and Medicine, CRC Press, USA, pp. 217-230.

25. Giorgi C, De Stefani D, Bononi A, Rizzuto R, Pinton P (2009) Structural and functional link between the mitochondrial network and the endoplasmic reticulum. Int J Biochem Cell Biol 41(10): 1817-1827.

26. Pinton P, Giorgi C, Siviero R, Zecchini E, Rizzuto R (2008) Calcium and apoptosis: ER- mitochondria Ca2+ transfer in the control of apoptosis. Oncogene 27(50): 6407-6418.

27. Okeke E, Dingsdale H, Parker T, Voronina S, Tepikin VA (2016) Endoplasmic reticulum-plasma membrane junctions: structure, function and dynamics. The journal of Physiology 594(11): 2837-2847. 